\title{
ACUAN DESAIN UNTUK KEGIATAN \& FASILITAS RUANG MENYUSUI PASAR KRAMAT JATI DAN PASAR MAYESTIK, JAKARTA
}

\author{
Ruth Euselfvita Oppusunggu' ${ }^{1}$, Anisa Rimba', ${ }^{1}$ Yenty Rahardjo ${ }^{1}$ \\ ${ }^{1}$ Desain Interior, School of Design, Universitas Pelita Harapan \\ 200rumahbesi@gmail.com, anisarimba13@gmail.com, yenty.rahardjo@uph.ed
}

\begin{abstract}
Abstrak
Ruang menyusui, pendukung peran ibu beraktivitas dan bekerja di luar rumah, menjadi ruang yang perlu ada di bangunan publik berdasarkan Permen Kesehatan RI No.15 Tahun 2013. Pasar rakyat sebagai bangunan publik juga menyediakan ruang menyusui dengan mengacu pada Permen PUPR 14/PRT/M/2017. Pasar rakyat Jakarta dapat dikelompokkan menjadi 2: pasar besar dan pasar kecil. Luas ruang menyusuinya seturut dengan jenis pasarnya. Pasar Mayestik dan Pasar Kramat Jati adalah subjek paper ini, representatif dari pasar besar Jakarta. Sementara itu, konsep ruang menyusui relatif baru dan cenderung tidak fungsional bagi pengguna pasar, pedagang dan pembeli wanita menyusui atau memiliki balita, karena ternyata aktivitas mereka dan balita mereka lebih dari sekedar menyusui dan membersihkan balita yang disediakan pada ruang menyusui yang ada. Paper ini memaparkan perjalanan pengabdian akademis Program Studi Desain Interior, melalui 8 minggu matakuliah Desain Masyarakat dan Lingkungan, dengan metode berpikir desain (design thinking) terhadap aspirasi pengguna untuk acuan desain ruang menyusui yang lebih kontekstual terhadap aktivitas beserta fasilitasnya. Pengabdian ini juga merupakan kelanjutan dari kolaborasi PD Pasar Jaya dan Desain Interior, School of Design, Universitas Pelita Harapan untuk Program CSR Desain Ruang Menyusui, serta PKM Internal Universitas Pelita Harapan untuk Mendesain Ruang Menyusui dan Perawatan Bayi di Pasar Tradisional DKI Jakarta.
\end{abstract}

Kata Kunci : ruang menyusui, pasar rakyat, fasilitas ibu dan anak, desain berorientasi pada pengguna, acuan desain

PENDAHULUAN

Paper ini merupakan seri dari 2 paper yang memiliki semangat dan pendahuluan yang sama. Paper yang lain berjudul Acuan Desain Partisi Ruang Menyusui Pasar Walang Baru, Pelita dan Cengkareng, Jakarta. Kedua paper merupakan bagian dari Prosiding PKM CSR Volume 2, Keduanya juga memiliki dasar metode yang sama, lalu selanjutnya berbeda konsentrasi karena berbeda karakteristik subjek PKM CSR, masalah dan potensi.
Asosiasi Ibu Menyusui Indonesia (2011) menyatakan bahwa Negara melindungi kegiatan ibu menyusui dan mengaturnya agar kegiatan ini dapat dilakukan di berbagai fasilitas umum, sarana kesehatan maupun perkantoran [1]. Pasar rakyat merupakan bangunan komersial, fasilitas umum regional, yang eksistensinya sedang tergerus oleh kehadiran pasar modern. Menurut Ardhanareswari dan Sitorus (2016), dalam lima tahun terakhir jumlah pasar rakyat berkurang $8,1 \%$ per tahun sementara pasar modern bertambah $3,1 \%$ per tahun, atau jumlah 13.500 pasar rakyat pada 2007 menjadi

Ekonomi, Sosial, dan Budaya

1075 
9.559 pasar rakyat pada 2015. Untuk mendukung daya saing pasar rakyat, pemerintah mendorong revitalisasi dan pembangunan pasar rakyat berstandar nasional (SNI) [2]. Semangat yang sama juga diusung oleh Perumda Pasar Jaya (PJ), organisator pasar rakyat Jakarta, seperti disampaikan oleh Pratomo (2018), bahwa pasar rakyat tidak hanya lokasi jual-beli tetapi juga wadah akivitas sosio-ekonomi-religi yang dilengkapi fasilitas dan salah satunya adalah ruang laktasi [3]. Humas Badan Standardisasi Nasional (2019) mencatat PJ telah memilik 16 pasar rakyat ber-SNI [4] dan diantaranya adalah Unit Pasar Besar (UPB) Kramat Jati dan Unit Pasar Besar (UPB) Mayestik yang merupakan subjek PKM CSR paper ini..

Ketika PKM CSR ini dimulai, PJ sedang sedang menyiapkan ruang menyusui pada kedua pasar. Kolaborasi PJ dan Desain Interior, Universitas Pelita Harapan Karawaci (DI UPH) bertujuan menjadikan ruang menyusui tidak hanya sesuai SNI tetapi juga didesain dengan baik. Kolaborasi PJ dan DI UPH ini merupakan bagian dari perjalanan kolaboratif keduanya sejak 2016. DI UPH melengkapi langkah PJ merevitalisasi pasar rakyat Jakarta melalui riset dan intervensi desain agar pasar rakyat menjadi ruang publik dan komersial yang inklusif dan inovatif: 1) 2016-2017: Merupakan bagian dari matakulliahTugas Akhir (TA) mahasiswi. Berupa commuity action plan untuk pemberdayaan komunitas dan pemangku kepentingan Pasar Santa serta intervensi desain agar Pasar Santa ramai kembali dan terus menjaga karakteristiknya sebagai pasar hipster-pasar produk kreasi lokal anak muda, seperti ditulis oleh Oppusunggu, Tjoeputri dan Katoppo (2018) [5], 2) 2018: Merupakan bagian dari PKM dan matakuliah Studio ruang publik inklusif bagi warga senior. Berupa riset dan intervensi desain wayfinding yang juga hasil kolaborasi dengan Lembaga Penelitian dan Pengabdian Masyarakat (LPPM) UPH. Agar Pasar Santa lebih ramah bagi pengunjung lanjut usia sebagai pengguna eksisting dan warga senior yang membutuhkan pasar sebagai wadah interaksi sosial, kultur dan budaya, seperti ditulis oleh Oppusunggu dan Monica (2018) [6], 3) 2018: Merupakan bagian dari PKM dan matakuliah Desain, Masyarakat dan Lingkungan
(DSE) fokus pasar rakyat. Juga hasil kolaborasi dengan LPPM UPH. Berupa riset dan pemberdayaan pedagang membangun kesadaran dan kemandirian kebersihan di Pasar Tebet Timur, seperti ditulis oleh Clorinda, Martina, dan Oppusunggu (2019) [7], 4) 2018: Merupakan bagian dari DSE fokus pasar rakyat. Berupa prototipe/proposal aplikasi ponsel Market Helper Indonesia yang menjaga dan meningkatkan pendapatan pedagang kecil pasar rakyat, petani, dan nelayan sekaligus mendukung diet sehat keluarga Indonesia, seperti dipresentasikan oleh Oppusunggu dan Martina pada 2019 Indonesia Development Forum, diselenggarakan Kementerian PPN /Bappenas [8], 5) 2019: Merupakan bagian dari PKM dan matakuliah DSE fokus pasar rakyat. Juga hasil kolaborasi dengan LPPM UPH untuk acuan desain ruang menyusui pasar rakyat yang berbagi fokus pada a) kegiatan dan fasilitas yang juga perlu diwadahi ruang menyusui, studi kasus di UPB Kramat Jati dan UPB Mayestik, dan b) partisi ruang menyusui yang responsif terhadap eksisting pasar rakyat, studi kasus Pasar Pelita, Pasar Walang Baru, Pasar Cengkareng.

Riset dan intervensi desain nomor 1-4 memiliki hal yang sama: a) fokus pada masalah dan potensi pasar, b) tim terdiri dari dosen pengampu dan mahasiswa matakuliah terkait, seperti TA, Studio atau DSE, c) waktu selama matakuliah berlangsung, 6 bulan untuk TA dan Studio, dan 8 minggu untuk DSE d) menggunakan mixed research method yang memberdayakan komunitas pasar rakyat.

Hal ini yang mendasari tim untuk menerima tantangan PJ (nomor 5), yaitu desain ruang menyusui untuk keempat pasar rakyat, diantaranya UPB Kramat Jati dan UPB Mayestik, yang sudah memiliki SNI. Dan untuk menjadikan hasil berdampak lebih luas, tim mengarahkan hasil kolaborasi ini menjadi acuan desain, sehingga dapat diaplikasikan ke pasar lain.

\section{METODE}

PKM CSR ini dilaksanakan oleh tim, terdiri dari 3 dosen dan 6 mahasiswi DI UPH. Metode yang digunakan adalah case study method (CSM) dan mixed research method (MRM). PKM CSR diselenggarakan sejak September 2018 sampai dengan Agustus 2019, lihat pada Tabel 1. CSM

$$
\text { Ekonomi, Sosial, dan Budaya }
$$

1076 
Tabel 1. Mixed research method

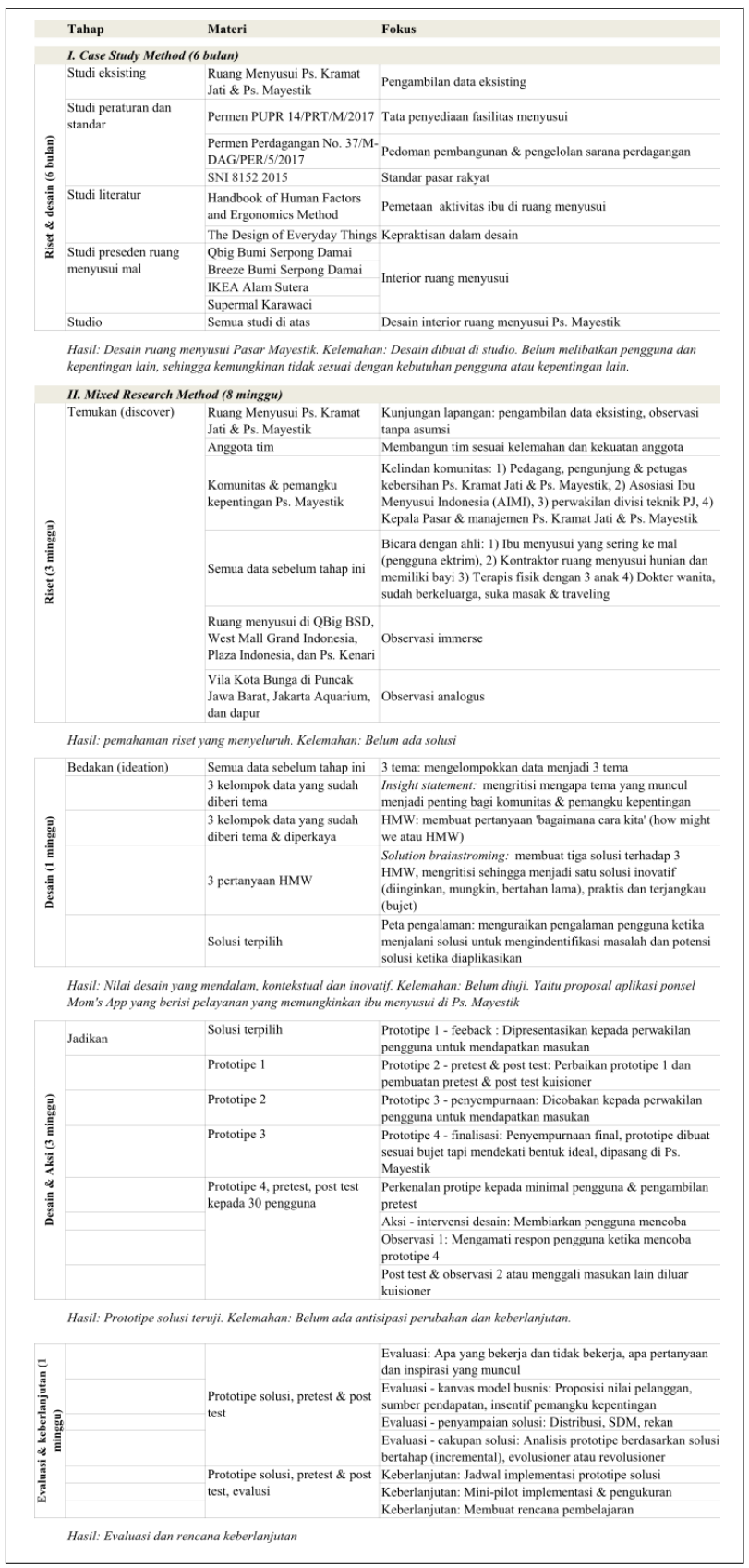

selama 6 bulan, terdiri dari studi peraturan, standar, literatur, preseden, dan studio (desain), lihat Gambar 1-2. Namun tahap ini dirasakan belum kontekstual karena tidak melibatkan pengguna, komunitas dan pemangku kepentingan lain. Maka tim lanjut ke tahap MRM. Metode ini terdiri dari riset, desain dan aksi. Berbeda dengan CSM, MRM dilakukan bersama mahasiswi selama 8 minggu matakuliah DSE. Progres menjadi progresif dan menyeluruh.

Katoppo and Sudradjat (2015) menjelaskan bahwa MRM merupakan gabungan dari berpikir desain (design thinking), desain partisipatif, dan prototipe. Metode ini memungkinkan penulis meneliti subjek menjadi inovasi kuantitatif atau eksperimental, dan desain partisiaptif atau pengalaman dan apresiasi. Maka, metode alternatif ini membantu penulis mencapai pemahaman subjek yang menyeluruh, mendalami nilai desain, dan inovasi yang responsif terhadap konteks sosial [8].

MRM memiliki 3 tahap: 1) temukan atau tahap riset, kelindan dan partisipasi komunitas 2) bedakan atau desain, dan 3) jadikan atau prototipe, aksi, evaluasi dan keberlanjutan, lihat Tabel 1.

Pada MRM tahap Jadikan/Ideation, tim membangun 3 pertanyaan yang mengandung masalah dan potensi, lalu memilih hanya satu pertanyaan untuk selanjutnya diteruskan menjadi solusi. Pertanyaannya, "bagaimana kita bisa membantu penjaga toko di Pasar Mayestik agar bisa melakukan aktivitas laktasi dan proses jual beli tetap berlangsung dan toko tetap aman?"

Tim mengajukan proposal aplikasi Mom's App yang menawarkan kegiatan pendukung beserta pelayanannya sehingga pengguna, khususnya pedagang, dapat menyusui bayinya, lihat Gambar 5. Kegiatan-kegiatan yang muncul dari Mom's App inilah yang menjadi acuan desain dan fasilitas ruang menyusui di UPB Kramat Jati dan UPB Mayestik.

\section{HASIL DAN PEMBAHASAN} adalah:

Berikut acuan desain dari PKM CSR ini

1. Penanda grafis yang sangat besar pada tampak ruang menyusui

Ruang menyusui berada dekat toilet dan ruang klinik, tetapi tidak banyak yang tahu terutama pengunjung. Hal ini terutama disebabkan oleh minimnya penanda dan informasi. Penanda grafis yang sangat besar pada tampak membuat ruang menyusui mudah dikenali dan diingat seperti desain yang diajukan oleh tim, lihat Gambar 2. 


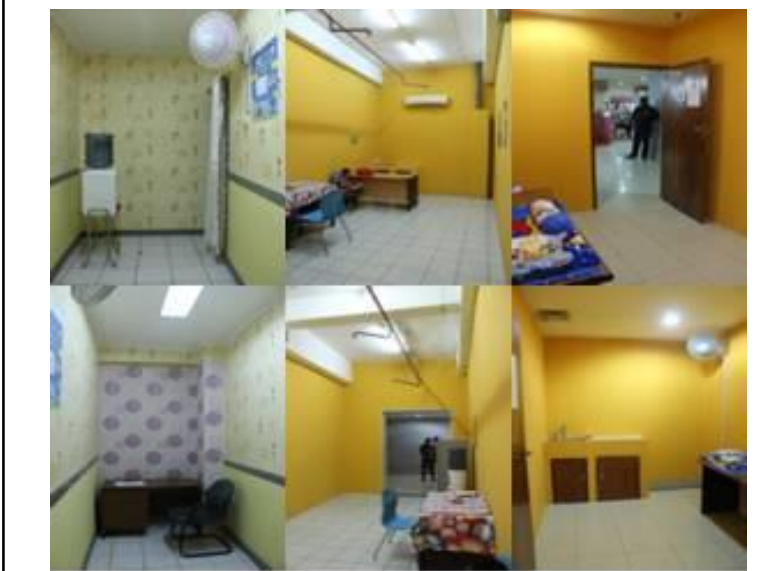

Gambar 1. Pengambilan data eksisting ruang menyusui. Kiri: Ps. Kramat Jati. Tengah: Ps. Mayestik Lt. 1. Kanan: Ps. Mayestik Lt. 2.

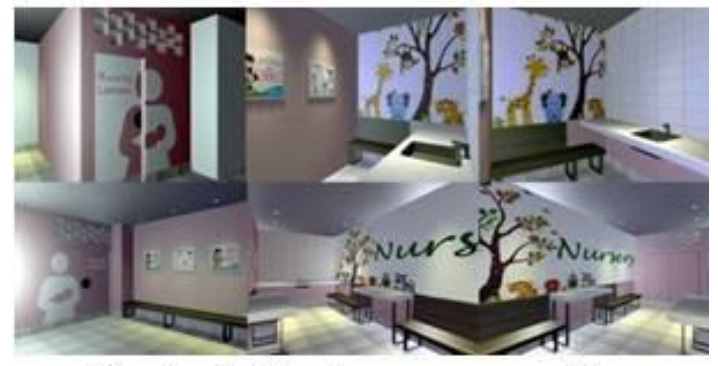

Gambar 2. Desain ruang menyusui Ps. Mayestik. Atas: Lantai 2. Bawah: Lantai 1.

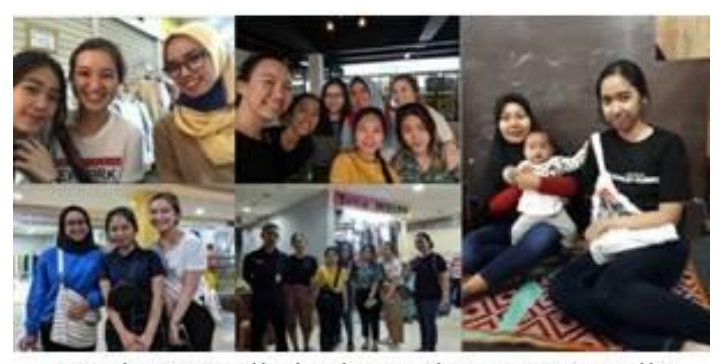

Gambar 3. Kelindan komunitas Ps. Mayestik. Kiri: Pedagang \& pembeli. Tengah: Perwakilan divisi teknik \& sekuriti. Kanan: Pejaga toko, ibu menyusui

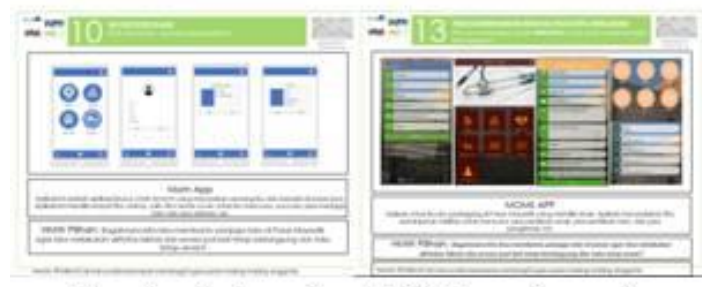

Gambar 4. Prototipe. Kiri: Prototipe awal. Kanan: Prototipe akhir setelah feedback.

2. Integrasi ruang menyusui dengan

\section{kegiatan pendukung lain}

Beberapa pengunjung masih datang menggunakan ruang menyusui. Namun tidak demikian dengan pedagang atau penjaga toko. Mereka memilih menyusui di toko karena tidak ingin meninggalkan toko. Pengguna menyambut baik bila ruang menyusui diintegrasikan dengan 1) Penitipan dan bermain anak. 2) Jasa penjaga toko pengganti, ketika ibu perlu meninggalkan toko untuk menyusui 3) Pengelolaan penyimpanan dan pengiriman ASI perah karena kulkas berada di ruang publik 4) Penyewaan kelengkapan perawatan bayi seperti gendongan, ayunan, mainan.

\section{Integrasi kelengkapan ruang menyusui sesuai SNI 81522015 dengan intensif atau komersialisasi \\ Kelengkapan seperti penyediaan air minum} (dispenser), penyimpanan ASI perah (kulkas), wadah pembuangan sampah seperti popok dan tisu basah (tong sampah), proteksi ketika ibu menyusui/memerah asi (kunci), dan tempat membersihkan tangan ibu dan bayi dari kotoran (wastafel), bisa disalahgunakan dan tidak efektif. Karena tidak ada pengawasan dan pelayanan. Kelengkapan ini perlu di bawah manajemen pengawasan dan pelayanan terkait dengan kepentingan ibu dan anak. Misalnya, kebersihan ruang menyusui terintegrasi dengan kebersihan toilet yang dikelola outsourcing, pembiayaan ketersediaan air minum terintegrasi dengan program promosi.

4. Potensi solusi sistematis dan teknologi (Mom's App) mengaktifkan dan menjaga keberlanjutan ruang menyusui

Mom's App mengajukan solusi nomor 2-4, yang memperkaya desain interior sehingga ruang menyusui juga mewadahi banyak kegiatan pendukung. Hal ini menambah efektivitas ruang menyusui sebagai ruang komersial urban.

\section{KESIMPULAN}

Paper ini menyimpulkan beberapa hal.

1. Mixed research method memperkaya acuan desain lebih kontekstual

Aplikasi SNI 8152-2015 lebih kontekstual ketika 1) desain interior ruang menyusui juga mewadahi kebutuhan ibu untuk menjaga bayi/anak

$$
\text { Ekonomi, Sosial, dan Budaya }
$$




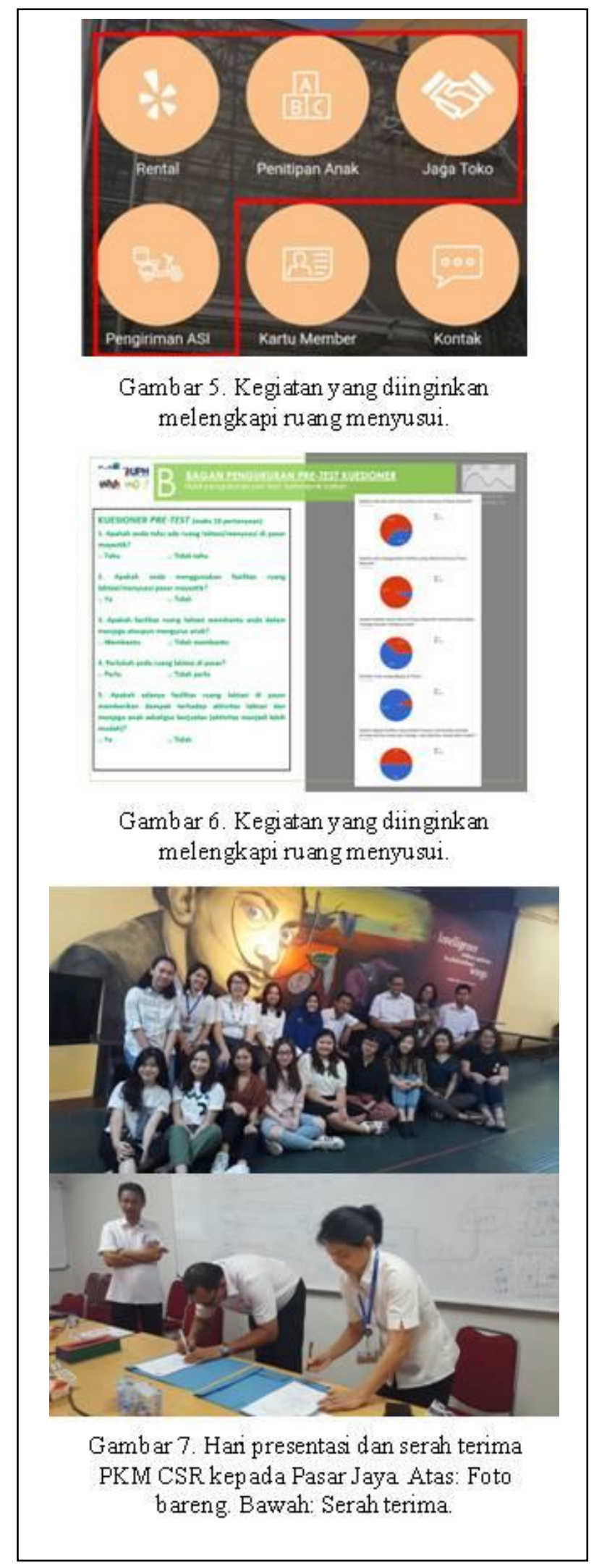

dan tokonya 2) furnitur kelengkapan ruang menyusui, seperti kulkas dan dispenser, menjadi inspirasi rencana dan tindakan efektivitas dan keberlanjutan yaitu 3) desain interior yang mewadahi integrasi pelayanan, pengelolaan dan promosi untuk nomor 1-2.

\section{Kolaborasi memperluas perspektif, menyelesaikan masalah dan memaksimalkan potensi}

Pada tahap case study research, acuan desain berfokus pada interior. Namun ketika berbagai latar belakang pemangku kepentingan terlibat, hasil akhir acuan desain meluas mencakup kegiatan-kegiatan yang juga perlu diwadahi desain interior. Solusi juga semakin menyeluruh karena menawarkan penyelesaian sistematis yang lebih kontekstual dengan kebutuhan pemangku kepentingan.

3. Mahasiswa dapat belajar menyeluruh tri dharma perguruan tinggi melalui PKM

Selain mahasiswa belajar membangun acuan desain berdasarkan mixed research method, mahasiswa juga dengan lengkap menerapkan panggilan tri dharma perguruan tinggi melalui keterlibatan mereka dalam PKM CSR ini.

\section{Konsistensi tema PKM membangun spesialisasi, menyempurnakan metode, dan memungkinkan pembuatan acuan yang lebih menyeluruh.}

Seperti penulis sampaikan pada pendahuluan, dengan ini DI UPH telah melaksanakan 6 kolaborasi untuk riset dan intervensi desain untuk pasar rakyat. Kesempatan ni memberikan DI UPH a) fokus pada masalah dan potensi desain interior pasar rakyat b) mengevaluasi dan menyempurnakan metode riset dan intervensinya c) dengan latar belakang riset dan intervensi DI UPH sebelum membuat acuan desain ini, DI UPH sudah memiliki bekal data, masalah dan potensi yang memperkaya keputusan/hasil.

\section{UCAPAN TERIMAKASIH}

Paper ini ada berkat dukungan Desain Interior Universitas Pelita Harapan Karwaci, Perumda Pasar Jaya, Lembaga Penelitian dan Pengabdian Masyarakat Universitas Pelita Harapan Karawaci, komunitas Pasar Kramat Jati \& Pasar Mayestik, pengampu matakuliah DSE, AIMI, narasumber, dan anggota tim: Phebe Valencia,

Ekonomi, Sosial, dan Budaya

1079 
Cynthia Marissa, Jacklyn A. Polii, Kezia Novita, Leony Calista, dan Natasha Aurel.

\section{REFERENSI}

1. Asosiasi Ibu Menyusui Indonesia (2011). Hak Ibu Menyusui Di Indonesia. aimiasi.org: https://aimiasi.org/layanan/lihat/hak-ibu-menyusui-diindonesia

2. Ardhanareswari dan Sitorus R. (2016). Baru 3 Pasar yang Lolos SNI. kemenperin.go.id: https://www.kemenperin.go.id/artikel/15055/Ba ru-3-Pasar-yang-Lolos-SNI

3. Buletin Pasar (2018). Keradaan Pasar Memberikan Manfaat Optimal Kepada Masyarakat. Buletin Pasar, Edisi VIII/September/2018, hlm. 8-10. pasarjaya.co.id: http://pasarjaya.co.id/_assets/files/buletin/Buleti n_Pasar_Edisi_September.pdf

4. Humas Badan Standardisasi Nasional (2019). Penerapan SNI Pasar Rakyat Tingkatkan Daya Saing Pasar Rejowinangun. bsn.go.id: http://www.bsn.go.id/main/berita/detail/9959/pe nerapan-sni-pasar-rakyat-tingkatkan-dayasaing-pasar-rejowinangun\#.XXxd4dUzbIU

5. Oppusunggu R.E., Tjoeputri M., dan Katoppo, M.L. (2018). A Study of Urban Placemaking, Evolution Changes at Pasar Santa Jakarta, International Journal on Liveable Space (Livas): https://www.trijurnal.lemlit.trisakti.ac.id/livas/a rticle/view/3900

6. Oppusunggu R.E. dan Monica (2018).
Studi Pasar sebagai Ruang Publik Inklusif bagi Lansia di Pasar Santa, Jakarta. Prosiding Seminar Nasional Desain Sosial Fakultas Desain Universitas Pelita Harapan 2018, hlm. 215-223, http://repository.uph.edu/2339/1/Prosiding_Sem inar_Nasional_Desain_Sosial_FD-

UPH_2018.pdf

7. Clorinda A., Martina W., dan Oppusunggu R.E. (2019). 'Ayooo Bebersih...! \& PSPT Helper':

Kampanye Kebersihan \& Prototipe Aplikasi Belanja On-line untuk Pasar Basah Tradisional PSPT Tebet. Prosiding Seminar Nasional

Desain Sosial Fakultas Desain Universitas Pelita Harapan 2019, http://snds.uph.edu/prosiding-seminar-nasionaldesain-sosial-2019/

8. Indonesia Development Forum (2019). Selected Speakers Indonesia Development Forum 2019. https://indonesiadevelopmentforum.com/2019/p age/winner

9. Katoppo M. dan Sudradjat I. (2015). Combining Participatory Action Research (PAR) and Design Thinking (DT) as an Alternative Research Method in Architecture. ProcediaSocial and Behavioral Sciences, Volume 184, hlm. $118-125$ 